\title{
Scientific and methodological approaches to the assessment of national research universities
}

\author{
Sergey Pronichkin ${ }^{1,2}$, Igor Mamai², Boris Savelyev², Zafar Vazirov² \\ ${ }^{1}$ Federal Research Center "Computer Science and Control" of Russian Academy of Sciences, \\ 40, Vavilov Street, Moscow, 119333 \\ Russia \\ ${ }^{2}$ Federal Center of Theoretical and Applied Sociology of Russian Academy of Sciences, \\ 24/35, Krzhizhanovsky Street, Moscow, 117218 \\ Russia \\ pronichkin@mail.ru
}

Received: May 3, 2021. Revised: November 21, 2021. Accepted: December 13, 2021. Published: January 7, 2022.

\begin{abstract}
The strategy of innovative development of Russia requires the formation of national research universities of the international level. Twenty-nine Russian universities have already been awarded this status. They are faced with a difficult task - to become the movers of priority areas for the development of science, technology, economic sectors, and the social sphere. The paper discusses the issue of assessing the quality of the activities of universities in the category "National Research University" (NRU). The disadvantages of existing approaches to assessing the activities of universities are highlighted. It is proposed to use self-assessment with the involvement of independent experts as a tool for assessing the activities of the NRU and its improvement. A process model and criteria for assessing the quality of the activities of a national research university have been developed. A mathematical model of the preferences of a decision-maker (DM) for a comprehensive assessment of the quality of NRU activities has been built. The model takes into account the individual and rational preferences of decision makers, as well as the balance of approaches and results to ensure the quality of NRU activities. Estimates of the numerical values of the parameters of the developed mathematical model are determined. For this, an experiment was planned and a D-optimal supersaturated design was built. The quality indicators of the developed model are calculated, which allow us to conclude that the developed model better describes the results of the experiment than the existing models.
\end{abstract}

Keywords-Criteria model, Decision making, Process model, Quality management.

\section{INTRODUCTION}

GOR a long time, Russian universities did not pay due Tattention to management issues, and only with the transition to market relations, most universities began to realize that effective university management is a key factor in the effective work of a university. Reduced budget funding and increased competition forced universities to change their strategy of activities. Non-profit organizations in Russia have ceased to consider themselves as closed systems that realize their statutory goals with the help of public funds. Quality orientation, anticipation of consumer needs has become one of the main strategies of their activities [1,2]. Universities turned to the study of the desires and needs of customers, work with various groups of consumers, diversification of activities, active promotion of services, formation of pricing policy, attraction of additional sources of funding. The strategy of innovative development of Russia required the formation of national research universities of the international level [3]. Twenty-nine Russian universities have already been awarded this status on a competitive basis. They are faced with a difficult task - to become the drivers of priority areas for the development of science, technology, economic sectors, and the social sphere.

In order for a national research university to provide products / services that are perfect in all respects, more effective management methods are first of all needed. But the more effective they are, the wider horizons they provide for improving performance, the more serious is the issue of tracking the dynamics of changes in work results, the list of criteria for assessing the activities of a national research university becomes more voluminous and diverse.

The criteria for evaluating the activities of the university form the basis of the system for ensuring the quality assurance 
of education. The provision of guarantees of the quality of education is understood as a set of auxiliary methods and means of assessing the quality of the higher education system, individual universities and programs [4]. In modern conditions, the following guarantees of the quality of education can be distinguished: rating, accreditation, assessment of the effectiveness of the intra-university quality management system (QMS).

The Ministry of Education and Science of the Russian Federation is pursuing a targeted policy of improving the quality of training specialists, increasing the competitiveness of the domestic education system, using modern management methods. In order to initiate a systematic approach to solving the problems of improving the quality of education, the Ministry of Education and Science of the Russian Federation in 2000 organized a competition "Quality Systems for Graduate Training" (CQS). During the entire period of the CQS, all universities of the category of the national research university took part in it. Most of the universities that participated in the CQS, despite the abundance of information they collect, need to create decision support systems to manage the quality of their activities.

\section{METHODS}

The decision-making process is central at all levels of management of the activities of a national research university (NRU). One of the key stages of the decision-making process is information preparation of the decision. At this stage, we must assess the state of the system in order to determine the degree to which the system has achieved the goal of the decision maker (DM). The goal of the decision maker is a comprehensive continuous improvement of the university's activities. This goal is dictated by decision makers by the modern paradigm of management of any organization, including a university - any organization should strive for system optimization [5, 6]. Systemic optimization is understood as meeting the long-term needs of all social groups associated with a community of interests with the organization. Thus, the construction of NRU management should be based not only on even the most objective numerical indicators, but on the basis of an understanding of the processes of achieving results, both quantitative and qualitative results. Relying only on the quantitative results of the decision maker, he will not see the system as a whole, due to the presence of emergent properties in it, which are not fundamentally deduced from quantitative indicators. Quantitative management stimulates short-term thinking and diverts energy from long-term improvement. Quantitative indicators are the main model for accreditation of Russian universities. Currently, most Russian universities use accreditation and rating indicators as criteria for assessing their performance [7].

The Ministry of Education and Science of the Russian Federation has established an annual reporting system for subordinate universities, which contains the accreditation indicators of the educational institution's activities achieved in the reporting year. Accreditation indicators are used for information and analytical support for decision-making on state accreditation of the Federal Service for Supervision in Education and Science.

Using data received from universities for the corresponding year, the National Accreditation Agency for Education sets thresholds for accreditation indicators of higher education institutions in the comparison group. Each university, using data on accreditation indicators, can assess its compliance with the accreditation criteria as a whole, using a special index.

At the request of the university, the National Accreditation Agency for Education prepares an analytical report for it. It helps to determine the degree of its readiness for state accreditation, compliance with the declared state accreditation status, as well as to conduct a comparative assessment of the results of its activities against the background of other singleprofile higher educational institutions in Russia.

In addition to the values of accreditation indicators, the report contains their graphical interpretation, namely a radial chart and a chart of ranking universities by accreditation indicator with the median and quartiles plotted on it. The report also presents the results of a discriminant analysis of accreditation indicators: the probability of a particular educational institution belonging to this type, the position of an educational institution on the plane of discriminant functions.

It is important to note that accreditation indicators are presented partly in a qualitative form (expert assessment with two levels of gradation), partly in quantitative form. Expert opinions are used to determine the accreditation status of an educational institution of the "higher education institution" type. The thresholds for accreditation indicators are based on average values. Most universities in the existing system of state accreditation in Russia intensify their activities once every five years in accordance with the terms of accreditation. This dramatically reduces the efficiency of decision-making at NRU. It is necessary to create a regular system of information preparation of managerial decisions at NRU. As information preparation of management decisions, it is proposed to use a conceptual model:

1) Every year the NRU prepares a report on its activities and sends it to independent experts. Experts prepare a response report, where they note the strengths and areas for improving the activities of the NRU, give marks according to the criteria.

2) Once every 5 years, the university, taking into account the annual self-assessments and on their basis, sends a summary report (with dynamics over the years) for examination. In this case, the expert opinion is drawn up after analyzing the reports for five years and the field examination of the university.

Existing approaches to assessing the quality of the activities of universities operate with characteristics $[8,9]$, reflecting mainly the results of their activities. At the same time, when conducting accreditation, the main focus is on the operating 
conditions of an educational institution, and such components as the process and results of educational activities are taken into account to a lesser extent.

In search of the optimal methodology for a comprehensive assessment of the activities of a national research university, it is proposed to take a systems approach as a basis, when decisions are made not only on the basis of quantitative or qualitative indicators (results), but also taking into account the analysis of the approaches used to achieve them (processes).

As a basis for developing criteria, it is advisable to use excellence models in the field of quality $[10,11]$. All models, without exception, are based on the "processes - result" concept.

\section{RESULTS}

A criterion model has been developed for a comprehensive assessment of the activities of the NRU, which consists of twelve criteria. When developing the criteria, the models of business excellence were taken into account [12, 13], criteria for programs for the creation and development of NRUs, as well as Russian and international experience in accreditation and rating of universities [14, 15].

The criteria of the developed model consist of two groups:

1) Criteria characterizing the capabilities of NRU to ensure the required quality of training of specialists $\left(z_{1}-\right.$ organizational structure; $z_{2}$ - leadership; $z_{3}$ - strategy; $z_{4}$ - potential; $z_{5}$ - resources; $z_{6}$ - process management).

2) Criteria characterizing the results achieved by the NRU $\left(z_{7}\right.$ - knowledge; $z_{8}$ - sustainability; $z_{9}$ - environment; $z_{10}$ - society; $z_{11}$ - science; $z_{12}$ - innovation).

The first group of criteria shows the resource potential of a NRU, its support and improvement on the part of the university. The second group of criteria shows how effectively the potential of NRUs is used in educational, scientific and other fields of activity.

The degree of achievement of the decision maker's goal is reflected in the quantitative assessment of his preferences for a comprehensive assessment of the quality of the NRU's activities according to the developed criteria. If the decision maker had a table that would contain all possible estimates of NRU and the corresponding preference estimates, then there would be no need to build a mathematical model of decision makers' preferences for a comprehensive assessment of the quality of NRU activities. The decision maker would simply choose the value of preference that corresponds to the multicriteria assessments of the NRU according to the criteria obtained as a result of the examination. But in our case, to build such a table, we need to consider a very large number of different options for assessing NRU, this is due to the dimension of the five-point scale used to evaluate NRU according to twelve criteria.

Another possibility is to select a number of multicriteria NRU assessments and determine preferences in them, in the hope that these assessments will cover the most frequently encountered states of NRU. This is possibly less timeconsuming task for the decision maker; nevertheless, the psychophysiological limitations of the decision maker remain in force. It is important to note that the decision-maker's system of preferences formalized in this way does not have any predictive power, since is built only according to those estimates that were directly considered by the decision maker.

The third possibility is to build a mathematical model in order to use it to predict the values of the decision maker's preferences in those states of the NRU that have not been studied directly by the decision maker. Thus, if it is not possible to measure the preference of the decision maker in each state, then it is possible at least to predict it. Moreover, with any multi-criteria assessment of the NRU.

It is necessary to make assumptions about the properties of the unknown to us mathematical model of the system of preferences of decision makers for a comprehensive assessment of the activities of NRU a priori, i.e. determine the structure of the mathematical model.

There are many different ready-made structures of mathematical models of decision makers' preferences for a comprehensive assessment of complex socio-economic systems. Various ways of generalizing all criteria into one, using the mathematical model of decision makers' preferences $[16,17]$.

The existing mathematical models of decision makers' preferences in relation to the problem of determining a comprehensive assessment of a university are the most popular linear convolution [18] - the principle of absolute concession, which gives an inadequate comprehensive assessment of a university that has extreme indicators in terms of criteria.

The existing approaches to the construction of a mathematical model of the decision maker's preferences are based on the fact that the decision maker in the dialogue chooses the postulated optimality principle that reflects the system of his preferences [19]. However, the decision maker may not possess the toolkit of the postulated optimality principles. Many of the principles require additional information from the decision maker, which is usually difficult for him to provide a priori. At the same time, the more a priori information is used to define a mathematical model, the more chances to get an adequate model.

The noted factors determine the feasibility of building a flexible mathematical model of decision makers' preferences, taking into account:

1) Rationality of decision makers' preferences - a multicriteria assessment of the quality of a NRU activity should be as close as possible to the maximum possible assessment and as far as possible from the minimum assessment.

2) Balance of approaches and results, in which the assessments according to the criteria should have a symmetric distribution. The balance is based on the results of the study of the assessments of the participants in the CQS. The study showed that the distribution of the 
assessments of the CQS laureates obeys a uniform distribution law, while for the rest of the participants there is no such distribution.

3) Individual preferences of decision makers towards a comprehensive assessment of the NRU.

The formalization of the rationality of decision makers' preferences was carried out using the TOPSIS method [20]; it is proposed to modify it by introducing various norms.

Balance formalization was carried out using variance. Since the analytical expression of balance should take a value equal to zero for the same criterion evaluations, and in the case of the maximum difference in the criterion evaluations, take the maximum value. One of the functions that meets these requirements is variance $D^{S}$. The individual preferences of the decision maker are taken into account by parametrizing the mathematical model of the decision maker's preferences.

The structure of the proposed mathematical model, taking into account the properties described above, has the following form (1).

$$
f\left(a_{p}\right)=(1-\lambda) \frac{D^{A I}\left(a_{p}\right)}{D^{A I}\left(a_{p}\right)+D^{I d}\left(a_{p}\right)}+\lambda \frac{D^{\max }-D\left(a_{p}\right)}{D^{\max }}
$$

where $a_{p}=\left(z_{p i}\right)_{i=1}^{I}$ is the multi-criteria assessment of the NRU based on the results of the $p$ th examination;

$z_{p i}$ - assessment of the NRU according to the results of the $p$ th examination according to the $i$ th criterion;

$D^{A I}\left(a_{p}\right)=\left(\sum_{i=1}^{I} \gamma_{i}^{k_{2}}\left|z_{i}^{A I}-z_{p i}\right|^{k_{2}}\right)^{\frac{1}{k_{2}}}-$ the distance of the multicriteria assessments of the NRU according to the results of the $p$ th examination from the anti-ideal point;

$D^{I d}\left(a_{p}\right)=\left(\sum_{i=1}^{I} \gamma_{i}^{k_{1}}\left(z_{i}^{I}-z_{p i}\right)^{k_{1}}\right)^{\frac{1}{k_{1}}}-$ the distance of the

multicriteria assessments of the NRU according to the results of the $p$ th examination from the ideal point;

$D^{S}$ - variance of multi-criteria assessments of NRUs based on the results of the $p$ th examination;

$D^{S}$ - the maximum value of the variance;

$k_{1}, k_{2}$ - indicator of the norm;

$\gamma_{i}$ - the importance of the $i$ th criterion;

$z_{i}^{I}=\left(\max _{z_{p i} \in Z_{i}} z_{p i}\right)_{p=1}^{P}-$ ideal point;

$z_{i}^{A I}=\left(\min _{z_{p i} \in Z_{i}} z_{p i}\right)_{p=1}^{P}-$ anti-ideal point;

$\lambda$ - model parameter, $\lambda \in(0,1)$.

The experiment should be planned and evaluated to determine the numerical values of the parameters $k_{1}, k_{2}$ and $\lambda$ of the mathematical model (1). And to do it with maximum efficiency, i.e. with a minimum number of questions to the decision maker, obtain maximum information about the influence of the varied values of the criteria on the parameters of the model (1) in order to evaluate them with maximum accuracy. To estimate the parameters of the model, the number of experiments is 29 , and to assess the predictive properties of the model, another 29 experiments were used. The experiment design size is 58 .

In order to obtain the maximum information about the influence of the varied values of the criteria on the parameters of the model, the experimental design was constructed as Doptimal [21], such a design allows the most efficient use of the volume of the criterion (factor) space to obtain the most accurate estimates of the parameters of the model (1). The Doptimal design maximizes the determinant of the information matrix (2).

$M(\xi, \vec{\theta})=\left(\sum_{s=1}^{n} \frac{\partial f\left(a_{s}, \theta\right)}{\partial \theta_{i}} \cdot \frac{\partial f\left(a_{s}, \theta\right)}{\partial \theta_{j}} \cdot w_{s}\right)_{i, j=1}^{3}$

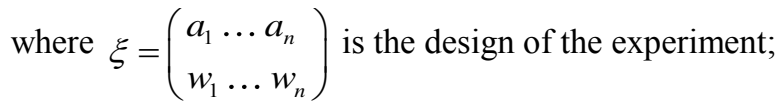

$\theta=\left(\lambda, k_{1}, k_{2}\right)-$ parameters of the model (1).

For D-optimal designs, the determinant of the information matrix does not depend on the parameters included in the model linearly $[22,23]$; in our case, the parameter $\lambda$ is set equal to 0 . However, the determinant of the information matrix depends on the values of the parameters $k_{1}$ and $k_{2}$, which are estimated. To overcome this contradiction, there are several standard approaches [24]: locally optimal, Bayesian and maximin. The maximin approach $\max _{\xi} \min _{\bar{\theta} \in \Omega}|M(\xi, \theta)|$ was used, since it is optimal if there is no a priori information about the parameters of the model, namely the approximate value $\theta$ from previous experiments or the probability distribution $\theta$.

The problem $\min _{\bar{\theta} \in \Omega}|M(\xi, \theta)|$ was solved using the graphicanalytical method.

$$
\text { The problem } \quad \max _{\xi}\left|M\left(\xi, \theta^{*}\right)\right|, \quad \text { where }
$$
$\theta^{*}=\arg \min _{\bar{\theta} \in \Omega}|M(\xi, \theta)|$, was solved using the approach of evolutionary computations - a genetic algorithm, this approach is optimal due to the large dimension of the space of variables and the nonlinearity of the objective function.

At each point in the design $\xi^{*}=\max _{\xi}\left|M\left(\xi, \theta^{*}\right)\right|$ an assessment was made $f\left(a_{p}\right), a_{p} \in \xi^{*}$. It is quite obvious that it is rather dangerous to be guided by the opinion of a single decision maker, and it is desirable to take into account the opinions of several specialists. Three experts from decision makers took part in the assessment. The importance of the model criteria was assessed $\left(z_{1}-0,086 ; z_{2}-0,081 ; z_{3}-\right.$ 
0,$084 ; z_{4}-0,079 ; z_{5}-0,083 ; z_{6}-0,072 ; z_{7}-0,087 ; z_{8}-$ 0,$\left.076 ; z_{9}-0,089 ; z_{10}-0,086 ; z_{11}-0,096 ; z_{12}-0,081\right)$.

The assessment $f\left(a_{p}\right)$ was carried out directly using a verbal-numerical scale. The empirical system of relations was a scale of order, consisting of five gradations. Metrized system of relations - the numerical part of the scale was built. A model example was developed that describes various states of NRU in the empirical system of relations, each decision maker expressed his opinion on the correspondence of a particular state to scores from 0 to 100 . The Delphi method was used to calculate the generalized estimates. Normalized values of estimates from 0 to 1 were used to calculate the estimates of parameters $\lambda, k_{1}$ and $k_{2}$ of the mathematical model (1). To estimate the parameters of the mathematical model (1), the least squares method was chosen. The grid search was used by the parameters of the mathematical model. The optimum was found for the values of the parameters $\hat{\lambda}=0.245, \hat{k}_{1}=2$ and $\hat{k}_{2}=2$.

\section{DISCUSSIONS}

The most important indicator of the quality of the object model is its adequacy [25, 26]. The model was tested using Fisher's test $[27,28]$. The hypothesis about the adequacy of the model (1) based on the design points used for its construction is not rejected $F_{1}=1.283<F_{T}=1.64$ at $\alpha=0.05$. For the design points used to evaluate the predictive properties of the model, the hypothesis is also not rejected $F_{2}=1.374<F_{T}=1.64$. Thus, the constructed model is adequate for all experiments in the constructed experimental design.

A comparative analysis of the explanatory and predictive properties of existing mathematical models for a comprehensive assessment of the activities of complex socioeconomic systems has been carried out [29, 30]. The explanatory property of the model is understood as the coefficient of determination $R_{1}$ calculated on the basis of the first group of design points, and the predictive property is understood as the coefficient of determination $R_{2}$ calculated on the basis of the second group of design points. In two respects, the developed model is more accurate than the existing ones:

The developed model $R_{1}^{2}=0.84, R_{2}^{2}=0.82$.

The principle of absolute assignment $R_{1}^{2}=0.73$, $R_{2}^{2}=0.75$.

Harrington's desirability function $R_{1}^{2}=0.37, R_{2}^{2}=0.41$. Ideal point principle (Euclidean norm) $R_{1}^{2}=0.79$, $R_{2}^{2}=0.76$.
Anti-ideal point principle (Euclidean norm) $R_{1}^{2}=0.52$, $R_{2}^{2}=0.57$.

As the conducted research has shown, the level lines of the developed model for high and low scores according to the criteria represent the level lines of the ideal and anti-ideal point principle, respectively. The decision maker's preference for a comprehensive assessment for average estimates by criteria corresponds to the level lines of the principle of absolute concession, and for extreme estimates by criteria it corresponds to the level lines of the ideal point principle, and this is due to the inclusion of variance in the mathematical model, which affects the steepness of the level lines in this area of the criterion space

\section{CONCLUSION}

The process of developing scientific and methodological approaches to assessing complex systems consists of the following main stages: facts - assumptions (empirical knowledge) - building a model - forecast (prediction) and its verification. To assess the NRU, all the indicated stages were passed. The quality indicators of the developed model allow us to conclude that the developed model describes the experimental results very well. At the same time, the coincidence of the most popular mathematical models with experimental data can hardly be considered satisfactory. NRU is not characterized only by a set of any criteria. In order to fully describe the educational and scientific activities of a NRU, an infinite number of criteria are needed. But for the effective management of the quality of the activities of a higher educational institution of the category "National Research University", not all possible, but the most important criteria are needed. Obviously, in addition to the criteria that are not important for us, there will always be criteria (indicators) that we do not know and / or do not know how to measure - evaluate [31, 32]. Moreover, the classification of the constituent criteria, like any other, is very conditional, and there is no sharp line between the different components of the proposed system of criteria. The developed mathematical model, together with the implementation of the conceptual model for assessing the activities of NRUs, will provide a mechanism for demonstrating the level of excellence of the activities of NRUs to stakeholders and, accordingly, increase the degree of trust on the part of all stakeholders and, reduce the volume of inspections conducted within the framework of state accreditation of NRUs in Russia.

\section{ACKNOWLEDGMENT}

The article is prepared with the financial support of the Russian Science Foundation, project № 19-78-10055.

\section{References}

[1] A. Sen, K. Kabak, and D. Kuzalic, "Democratization of University Management for Quality Higher Education," 
Procedia - Social and Behavioral Sciences, vol. 58, pp. 1491-1504, 2012.

[2] I. Lapina, I. Kairisa, and D. Aramina, "Role of Organizational Culture in the Quality Management of University," Procedia - Social and Behavioral Sciences, vol. 213, pp. 770-774, 2015.

[3] N. Matveeva, I. Sterligov, and M. Yudkevich, "The effect of Russian University Excellence Initiative on publications and collaboration patterns," Journal of Informetrics, vol. 15, pp. 1-15, 2020.

[4] J. Weinrib, and G. Jones, "Largely a matter of degrees: Quality assurance and Canadian universities," Policy and Society, vol. 33, pp. 225-236, 2014.

[5] J. Hays, V. Pereseina, and J. Saha, "Lessons in Sustainable Process Paradigm. A case study from Dubai," The International Journal of Management Education, vol. 18, pp. 1-9, 2020.

[6] A. Pohlmann, and V. Kaartemo, "Research trajectories of Service-Dominant Logic: Emergent themes of a unifying paradigm in business and management," Industrial Marketing Management, vol. 63, pp. 53-68, 2017.

[7] T. Sidorenko, and T. Gorbatova, "Efficiency of Russian Education Through the Scale of World University Rankings," Procedia - Social and Behavioral Sciences, vol. 166, pp. 464-467, 2015.

[8] V. Ivancevic, and I. Lukovic, "National university rankings based on open data: A case study from Serbia," Procedia Computer Science, vol. 126, pp. 1516-1525, 2018.

[9] M. Samuel, C. Vasquez, and D. Cabrera, "Clustering of Top 50 Latin American Universities in SIR, QS, ARWU, and Webometrics Rankings," Procedia Computer Science, vol. 160, pp. 467-472, 2019.

[10]A. Thurlow, A. Kushniryk, and A. Simon, "Evaluating excellence: A model of evaluation for public relations practice in organizational culture and context," Public Relations Review, vol. 43, pp. 71-79, 2017.

[11] M. Hamid, M. Abdullah, and H. Ahmad, "Conceptual Framework of Innovation Excellence Model for Higher Education Institutions," Procedia - Social and Behavioral Sciences, vol. 174, pp. 2846-2848, 2015.

[12] J. Mantilla, A. Zarzuelo, and F. Cruz, "Do ISO:9001 standards and EFQM model differ in their impact on the external relations and communication system at schools?," Evaluation and Program Planning, vol. 80, pp. 1-17, 2020.

[13]D. Hidiroglu, "Self- assessment Performance Measurement in Construction Companies: An Application of the EFQM Excellence Model on Processes and Customer Stages," Procedia Computer Science, vol. 158, pp. 844-851, 2019.

[14] M. Samuel, C. Vasquez, and D. Cabrera, "Clustering of Top 50 Latin American Universities in SIR, QS, ARWU, and Webometrics Rankings," Procedia Computer Science, vol. 160, pp. 467-472, 2019.

[15] C. Esparrells, and E. Malea, "Do the technical universities exhibit distinct behaviour in global university rankings? A Times Higher Education (THE) case study," Journal of
Engineering and Technology Management, vol. 48, pp. 97-108, 2018.

[16] B. Millot, "International rankings: Universities vs. higher education systems," International Journal of Educational Development, vol. 40, pp. 156-165, 2015.

[17] G. Olcay, and M. Bulu, "Is measuring the knowledge creation of universities possible?: A review of university rankings," Technological Forecasting and Social Change, vol. 123, pp. 153-160, 2016.

[18]K. Pavlina, "Webometric Ranking of European Universities," Procedia - Social and Behavioral Sciences, vol. 46, pp. 3788-3792, 2012.

[19]P. Kunsch, and A. Ishizaka, "Multiple-criteria performance ranking based on profile distributions: An application to university research evaluations," Mathematics and Computers in Simulation, vol. 154, pp. 48-64, 2018.

[20]B. Meniz, "An advanced TOPSIS method with new fuzzy metric based on interval type-2 fuzzy sets," Expert Systems with Applications, vol. 186, pp. 1-11, 2021.

[21] G. Dutta, and R. Ray, "D- and E-optimal blocked main effects plans with unequal block sizes when n is odd," Statistics \& Probability Letters, vol. 107, pp. 37-43, 2015.

[22]M. Jacroux, "On the D-optimality of orthogonal and nonorthogonal blocked main effects plans," Statistics \& Probability Letters, vol. 81, pp. 116-120, 2011.

[23] Y. Jung, and I. Lee, “Optimal design of experiments for optimization-based model calibration using Fisher information matrix," Reliability Engineering \& System Safety, vol. 216, pp. 1-15, 2021.

[24] C. Berding, W. Kleider, and R. Gossl, "DoPE: D-optimal planning \& experimentation the tool for experimental design in research and development," Computational Statistics \& Data Analysis, vol. 21, pp. 705-710, 1996.

[25] S. Nakagawa, P. Johnson, and H. Schielzeth, "The coefficient of determination $\mathrm{R}^{2}$ and intra-class correlation coefficient from generalized linear mixedeffects models revisited and expanded," Journal of The Royal Society Interface, vol. 14, pp. 1-11, 2017.

[26] E. Kasuya, "On the use of R and R squared in correlation and regression," Ecological Research, vol. 34, pp. 235236, 2019.

[27] W. Hamalainen, "New upper bounds for tight and fast approximation of Fisher's exact test in dependency rule mining," Computational Statistics \& Data Analysis, vol. 93, pp. 469-482, 2016.

[28] D. Lima, and R. Barros, "Concept drift detection based on Fisher's Exact test," Information Sciences, vol. 442, pp. 220-234, 2018.

[29] J. Ezzabadi, M. Saryazdi, and A. Mostafaeipour, "Implementing Fuzzy Logic and AHP into the EFQM model for performance improvement: A case study," Applied Soft Computing, vol. 36, pp. 165-176, 2015.

[30] O. Oleghe, and K. Salonitis, "Improving the Efficacy of the Lean Index through the Quantification of Qualitative Lean Metrics," Procedia CIRP, vol. 37, pp. 42-47, 2015.

[31] R. Reinhardt, and S. Pronichkin, "The realist paradigm of energy diplomacy in the Russian scientific tradition and its 
practical applicability," MGIMO Review of International Relations, vol. 1, pp. 94-109, 2018.

[32] I. Jonek, A. Musiol, and M. Wolny, "Does motivation matter in evaluation of research institutions? Evidence from Polish public universities," Technology in Society, vol. 67, pp. 1-18, 2021.

\section{Creative Commons Attribution License $\mathbf{4 . 0}$}

(Attribution 4.0 International, CC BY 4.0)

This article is published under the terms of the Creative Commons Attribution License 4.0

https://creativecommons.org/licenses/by/4.0/deed.en_US 